\title{
A Reproducible Capillary Gas Chromatographic Technique for the Determination of Specific Terpenes in Grape Juice and Wine
}

\section{J. Marais}

Viticultural and Oenological Research Institute, Private Bag X5026, 7600 STELLENBOSCH, Republic of South Africa.

Submitted for publication: January 1986

Accepted for publication: March 1986

Keywords: Gas chromatography, terpenes, grapes, wine

\begin{abstract}
A reliable and highly reproducible technique for the Freon 11 extraction of 16 terpenes from grape juice and wine and their gas chromatographic analyses is presented. Terpene concentrations were calculated as relative values by means of an internal standard. Standard deviations of the terpenes analysed varied between $1,2 \%$ and $13,9 \%$ for non-settled grape juice and between $2,0 \%$ and $5,2 \%$ for wine. Variation in gas chromatographic retention times was between 0,04 and 0,1 minutes. The freon extracts of grape juice and wine could be stored at minus $12^{\circ} \mathrm{C}$ for up to six days without marked changes occurring in the relevant terpene concentrations.
\end{abstract}

Terpenes are important aroma constituents of muscat, as well as non-muscat cultivars. Approximately 50 terpenes, as well as a number of compounds of terpenic origin which have been identified in grapes and wines, were reviewed by Marais (1983). Before research on the effect of various factors, such as cultivar, region, grape maturity and juice treatments on terpene concentrations and wine quality can be conducted meaningfully, an accurate and reproducible method for terpene analysis is needed. Various methods for the determination of terpenes have been used (Schreier \& Drawert, 1974; Rapp, Hastrich \& Engel, 1976; Williams, Strauss \& Wilson, 1980). The aim of this study was to adapt existing techniques in order to satisfy the specific objectives of local terpene research.

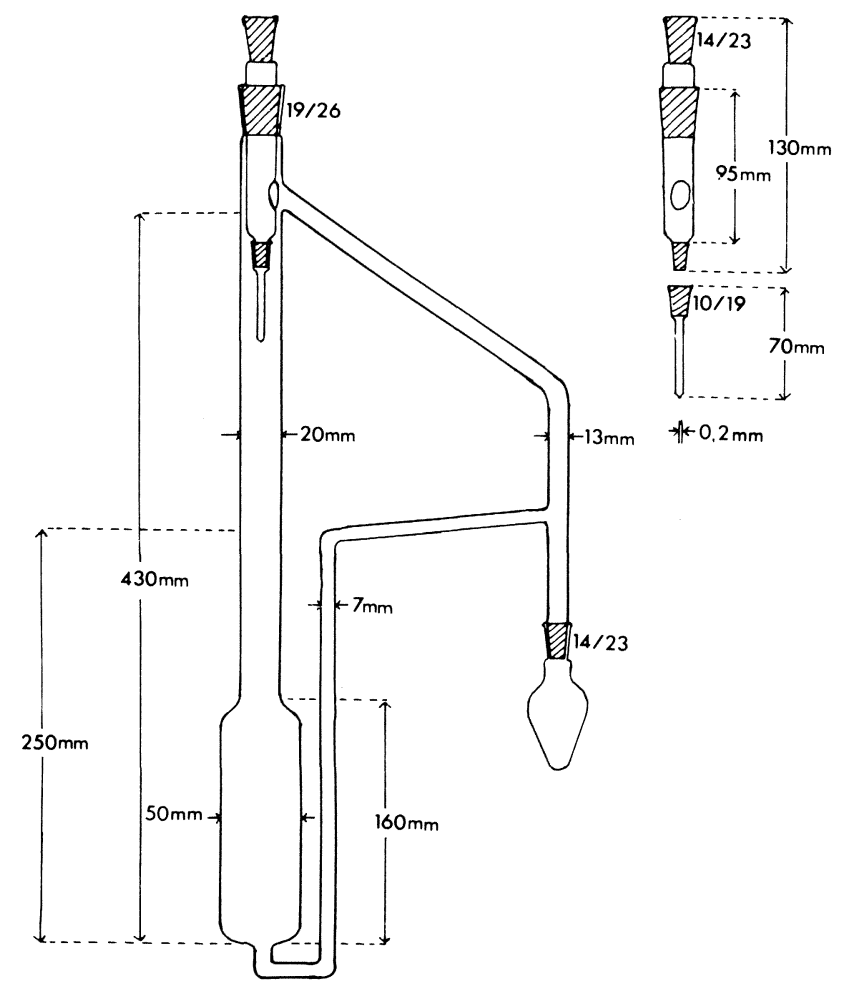

FIG. 1

Extraction apparatus for the continuous Freon 11 extraction of $250 \mathrm{~m} /$ grape juice and wine samples with details of collecting funnel.

\section{MATERIALS AND METHODS}

Samples of non-settled juice and wine of Muscat d'Alexandrie were used in this study.

\section{Extraction apparatus:}

Juice and wine samples $(250 \mathrm{ml})$ were extracted by Freon 11 in a continuous extractor (Fig. 1), a modified version of the apparatus used by Rapp et al. (1976). The redesigned collecting funnel ensures easier handling, a more stable system and a high degree of reproducibility. The internal diameter of the funnel tip was $0,2 \mathrm{~mm}$ to facilitate the formation of a consistent spray of uniform droplets. The length of the funnel may vary, depending on the density of the sample extracted, but it should be such that, when installed, the tip is $5 \mathrm{~mm}$ to $10 \mathrm{~mm}$ below the surface of the sample.

\section{Extraction technique:}

1) Samples were cooled to approximately $0^{\circ} \mathrm{C}$ prior to extraction to lessen the degree of emulsification at the freon/water interface which, if present, drastically influences reproducibility.

2) The internal standard, $0,5 \mathrm{~m} l$ 2-ethyl hexanol $(80 \mu \mathrm{g} / \mathrm{l})$ was added to $250 \mathrm{~m} l$ of the sample and mixed for 30 seconds in a measuring flask.

3) Freon $11(20 \mathrm{~m} l)$ was poured into the extraction apparatus and a tuft of sylilated glass wool placed on the freon surface to prevent emulsification during extraction. The sample containing the internal standard was then carefully poured into the extraction apparatus.

4) The extraction unit was installed with its bottom immersed $50 \mathrm{~mm}$ in ice to prevent the formation of emulsion. The collecting funnel and a condensor, through which water at approximately minus $5^{\circ} \mathrm{C}$ was circulated, were fitted to the extraction unit.

5) A $25 \mathrm{ml}$ pear shaped collecting flask, containing $20 \mathrm{~m} /$ freon, was fitted to the extraction unit and immersed in a waterbath at $35^{\circ} \mathrm{C}$.

6) Extraction was done for 20 hours at a controlled room temperature of $19^{\circ} \mathrm{C}$ to $20^{\circ} \mathrm{C}$.

\section{Concentration of freon extracts:}

1) A Vigreux $(270 \times 20 \mathrm{~mm})$ and an air condensor (550 $\mathrm{x} 13 \mathrm{~mm}$ ) were installed onto the flask containing the extract to facilitate reflux. The flask was held in a waterbath at $35^{\circ} \mathrm{C}$, room temperature controlled at $20^{\circ} \mathrm{C}$ or lower and the extract concentrated to ap- 
proximately $2 \mathrm{~m} l$.

2) After concentration, the flask was placed in solid $\mathrm{CO}_{2}$ to freeze out possible traces of water from the extract. The dry extract was then transferred to a $3 \mathrm{ml}$ pear shaped flask with a tapered tip by means of a Pasteur pipette. A small air condensor $(220 \mathrm{x}$ $8 \mathrm{~mm}$ ) with a spiral made of 1 x $0,5 \mathrm{~mm}$ Teflon strip was fitted onto the flask and concentration was continued under partial reflux to approximately $0,1 \mathrm{~m} l$. Concentration time was approximately 45 minutes.

3) Extracts were stored at minus $12^{\circ} \mathrm{C}$ prior to analysis.

\section{Gas chromatographic conditions:}

Gas chromato-: Hewlett Packard 5880A with autograph matic dual integrators

Column : $50 \mathrm{~m}$ x $0,31 \mathrm{~mm}$ (i.d.), Carbowax $20 \mathrm{M}$ fused silica capillary column (Hewlett Packard).

Injection tem-

perature $\quad: 200^{\circ} \mathrm{C}$

Detector : Flame ionization

Detector tem-

perature $: 250^{\circ} \mathrm{C}$

Temperature $: 60^{\circ} \mathrm{C}$ for 10 minutes.

program $\quad 60^{\circ} \mathrm{C}$ to $190^{\circ} \mathrm{C}$ at $1^{\circ} \mathrm{C} / \mathrm{min}$.

$190^{\circ} \mathrm{C}$ for 30 minutes.

Carrier gas : Helium

Column flow

rate $: 1,5 \mathrm{ml} / \mathrm{min}$.

Split flow rate $: 120 \mathrm{~m} l / \mathrm{min}$

Split ratio $: 90: 1$

Septum purge $: 6 \mathrm{ml} / \mathrm{min}$.

Hydrogen flow

rate

$: 30 \mathrm{ml} / \mathrm{min}$.

Air flow rate $: 300 \mathrm{ml} / \mathrm{min}$.

Injection

volume $: 1 \mu \mathrm{l}$

Overall analysis

time :170 minutes.

\section{Calibration of terpenes:}

The response factor for the internal standard $\left(f_{a}=1\right)$ was also used for the terpenes analysed and terpene concentrations were consequently calculated as relative concentrations. The internal standard calibration method, used by the HP 5880 computer entails the following calculation.

Concentration $(b)=$ area (b) $x$ factor $(b) \times$ concentration (a) area (a) $x$ factor (a)

$\mathrm{a}=$ Internal standard

$\mathrm{b}=$ Unknown compound

Confirmation of terpene identities by mass spectrometry:

Identities of terpenes were confirmed by comparing their mass spectra and retention times with those of authentic standards which were analysed under similar conditions.

GC-MS conditions were as follows:

GC-MS : Finnigan 4021

Column $\quad: 100 \mathrm{~m} \times 0,5 \mathrm{~mm}$ (i.d.), SP-1000 glass SCOT column

Injection

temperature $: 220^{\circ} \mathrm{C}$

Interface

temperature $: 220^{\circ} \mathrm{C}$
Manifold

temperature $: 90^{\circ} \mathrm{C}$

Temperature $: 60^{\circ} \mathrm{C}$ for 10 minutes.

program $\quad 60^{\circ} \mathrm{C}$ to $180^{\circ} \mathrm{C}$ at $1^{\circ} \mathrm{C} / \mathrm{min}$.

$180^{\circ} \mathrm{C}$ for 40 minutes.

Carrier gas : Helium

Column flow

rate

$: 2,2 \mathrm{ml} / \mathrm{min}$.

Split ratio $\quad: 10: 1$.

Electron energy : $70 \mathrm{eV}$

Electron

multiplier

voltage : :1200 volts

Scanning rate :From 35 to 350 Amu each second with a 0,1 second delay between scans

\section{Tests performed:}

Reproducibility of gas chromatographic determination of terpene concentrations, repeatability of terpene retention times and the storage ability of freon extracts of grape juice and wine were investigated.

\section{RESULTS AND DISCUSSION}

Examples of the gas chromatographic analyses of a Muscat d'Alexandrie non-settled juice and wine are shown in Figures 2 and 3 respectively. The relevant terpenes together with their corresponding peak numbers, are listed in Table 1.

Reproducibility of gas chromatographic analyses of specific terpenes in non-settled grape juice and wine is given in Tables 2 and 3 respectively.

These clearly show that, with respect to the terpenes analysed, the method gives highly reproducible results for juice and wine samples. With the exception of limonene $(13,9 \%)$, 4-terpineol $(10,9 \%)$ and citronellol $(13,8 \%)$, the average standard deviation was $4,0 \%$ for the rest of the terpenes analysed in juice (Table 2). The above-mentioned three standard deviations are, how-

TABLE 1

Terpenes analysed in Muscat d'Alexandrie non-settled juice and wine.

\begin{tabular}{l|c}
\hline \multicolumn{1}{c|}{ Terpene } & $\begin{array}{c}\text { Peak } \\
\mathrm{nr}\end{array}$ \\
\hline 2,6,6-Trimethyl-2-vinyl-tetrahydropyran & 25 \\
Limonene & 42 \\
trans-5-(2-Hydroxy-isopropyl)-2-methyl-2-vinyl-tetrahydrofu- \\
ran (trans-Furan linalool oxide) \\
cis-5-(2-Hydroxy-isopropyl)-2-methyl-2-vinyl-tetrahydrofuran \\
(cis-Furan linalool oxide) & 87 \\
Nerol oxide & 95 \\
2-Ethyl hexanol (internal standard) & 96 \\
Linalool & 101 \\
4-Terpineol & 114 \\
Hotrienol & 123 \\
alpha-Terpineol & 129 \\
trans-5-Hydroxy-2,6,6-trimethyl-2-vinyl-tetrahydropyran & 147 \\
(trans-Pyran linalool oxide) & \\
cis-5-Hydroxy-2,6,6-trimethyl-2-vinyl-tetrahydropyran (cis- \\
Pyran linalool oxide) & 157 \\
Citronellol & 162 \\
Nerol & 164 \\
Geraniol & 169 \\
3,7-Dimethylocta-1,5-dien-3,7-diol (Terpene diol-1) & 181 \\
3,7-Dimethylocta-1,7-dien-3,6-diol (Terpene diol-2) & 197 \\
trans-Geranic acid & 231 \\
\hline & 269 \\
\hline
\end{tabular}




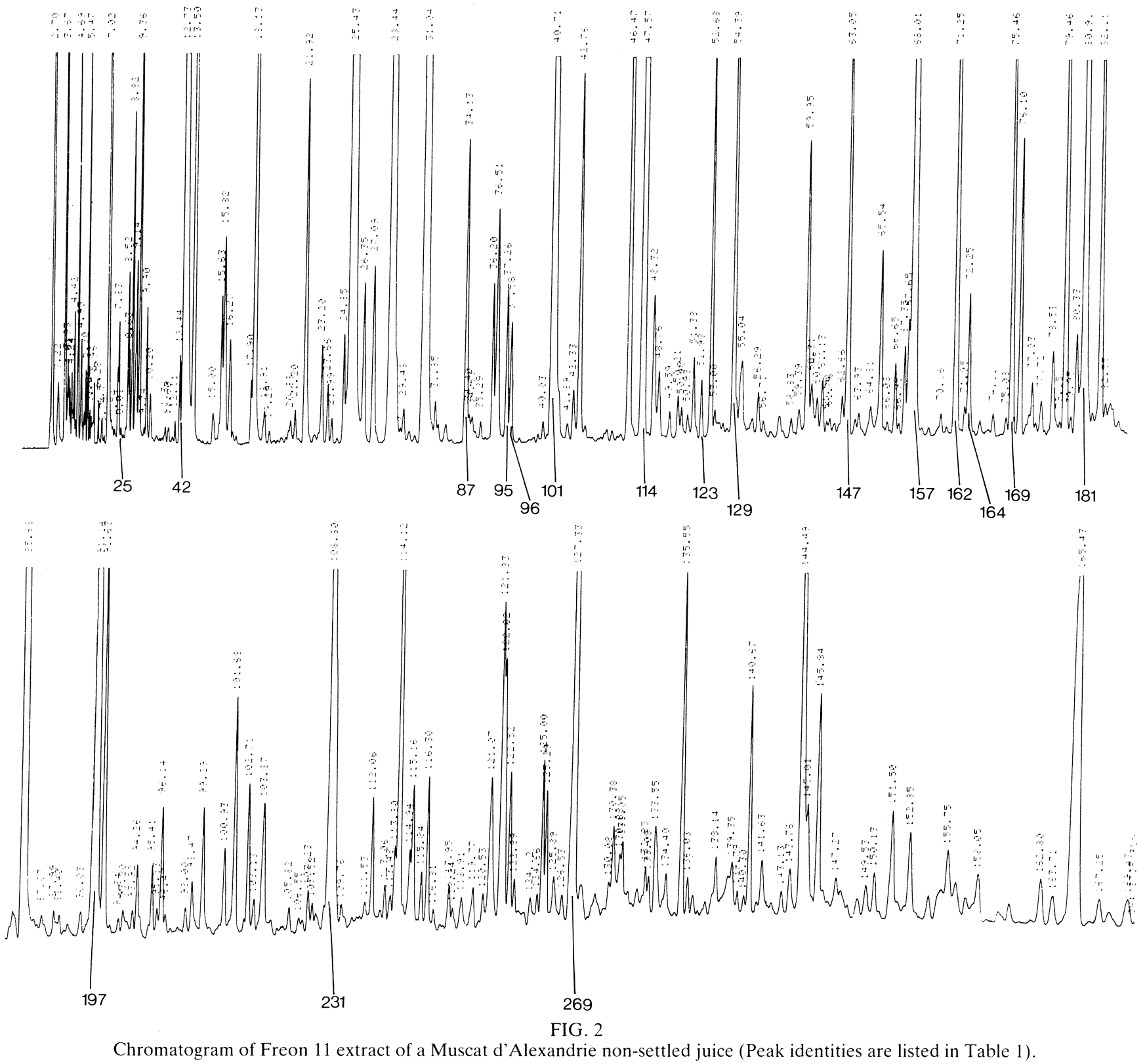

TABLE 2

Reproducibility of gas chromatographic analyses of terpenes in Muscat d'Alexandrie non-settled juice

\begin{tabular}{|c|c|c|c|c|c|c|c|c|c|c|c|c|}
\hline \multirow[b]{2}{*}{ Terpene } & \multicolumn{10}{|c|}{ Terpene concentration $(\mu \mathrm{g} / l)$} & \multicolumn{2}{|c|}{$\begin{array}{l}\text { Standard } \\
\text { deviation }\end{array}$} \\
\hline & $1^{\mathrm{a}}$ & 2 & 3 & 4 & 5 & 6 & 7 & 8 & 9 & 10 & $(\mu \mathrm{g} / l)$ & $\%$ \\
\hline Limonene & 0,90 & 1,13 & 1,08 & 0,99 & 0,96 & 1,04 & 0,98 & 1,06 & 1,43 & 1,03 & 0,15 & 13,9 \\
\hline trans-Furan linalool oxide & 5,52 & 5,74 & 5,82 & 5,72 & 5,66 & 5,54 & 5,60 & 5,39 & 5,81 & 5,58 & 0,14 & 2,4 \\
\hline cis-Furan linalool oxide & 3,85 & 3,84 & 3,93 & 3,97 & 3,87 & 3,78 & 3,89 & 3,80 & 4,05 & 3,82 & 0,08 & 2.2 \\
\hline Linalool & 171,20 & 169,63 & 174,51 & 177,73 & 173,06 & 168,54 & 174,92 & 168,75 & 174,52 & 168,74 & 3,24 & 1.9 \\
\hline 4-Terpineol & 1,10 & 1,22 & 1,26 & 1,04 & 1,16 & 1,06 & 0,97 & 0,96 & 0,90 & 1,17 & 0,12 & 10,9 \\
\hline Hotrienol & 7,52 & 7,34 & 7,76 & 8,95 & 8,01 & 9,52 & 8,62 & 7,72 & 8,62 & 7,77 & 0,71 & 8,6 \\
\hline alpha-Terpineol & 9,24 & 9,25 & 9,48 & 9,46 & 9,12 & 9,31 & 9,18 & 9,30 & 9,22 & 9,36 & 0.11 & 1,2 \\
\hline trans-Pyran linalool oxide & 108,34 & 109,73 & 115,80 & 113,91 & 107,39 & 109,89 & 111,68 & 105,24 & 108,26 & 108,96 & 3,13 & 2,8 \\
\hline cis-Pyran linalool oxide & 16,93 & 17,80 & 18,80 & 17,90 & 17,61 & 18,04 & 18,27 & 16,63 & 17,81 & 17,95 & 0,62 & 3,5 \\
\hline Citronellol & 1,98 & 2,39 & 2,50 & 2,02 & 2,51 & 2,54 & 2,81 & 1,87 & 2,46 & 2,80 & 0,33 & 13,8 \\
\hline Nerol & 18,29 & 17,48 & 18,24 & 18,65 & 17,92 & 17,89 & 18,14 & 17,45 & 17,20 & 17,81 & 0,44 & 2,5 \\
\hline Geraniol & 102,93 & 94,55 & 98,15 & 101,04 & 97,05 & 96,62 & 99,46 & 95,89 & 93,37 & 98,64 & 2,91 & 3,0 \\
\hline Terpene diol-1 & 185,72 & 189,15 & 220,30 & 163,36 & 173,88 & 177,78 & 187,25 & 190,32 & 199,04 & 183,82 & 15,27 & 8,2 \\
\hline Terpene diol-2 & 35,64 & 37,12 & 43,99 & 33,84 & 35,09 & 37,88 & 38,27 & 36,65 & 40,32 & 36,82 & 2,88 & 7,7 \\
\hline trans-Geranic acid & 66,73 & 60,27 & 64,53 & 69,49 & 60,94 & 63,34 & 65,52 & 61,78 & 61,34 & 63,63 & 2,89 & 4,5 \\
\hline
\end{tabular}

${ }^{a}$ The juice was extracted independently ten times and each extract analysed

Terpene concentrations are expressed as relative concentrations, calculated with the same calibration factor, i.e. $F_{a}=1$ 

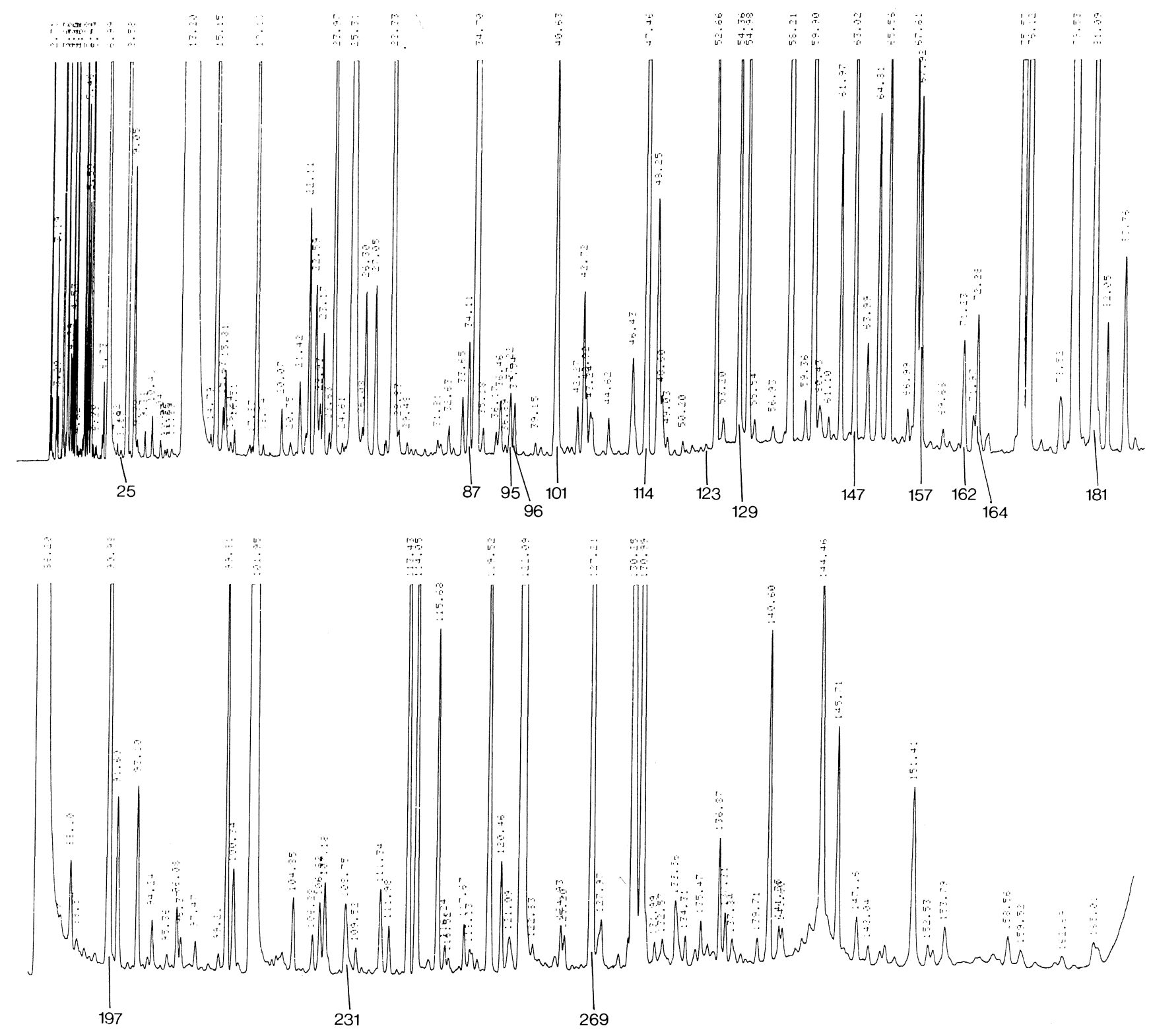

FIG. 3

Chromatogram of Freon 11 extract of a Muscat d'Alexandrie wine (Peak identities are listed in Table 1).

TABLE 3

Reproducibility of gas chromatographic analyses of terpenes in Muscat d'Alexandrie wine

\begin{tabular}{|c|c|c|c|c|c|c|c|c|c|c|c|c|}
\hline \multirow[b]{2}{*}{ Terpene } & \multicolumn{10}{|c|}{ Terpene concentration $(\mu \mathrm{g} / l)$} & \multicolumn{2}{|c|}{$\begin{array}{l}\text { Standard } \\
\text { deviation }\end{array}$} \\
\hline & $1^{\text {a }}$ & 2 & 3 & 4 & 5 & 6 & 7 & 8 & 9 & 10 & $(\mu \mathrm{g} / l)$ & $\%$ \\
\hline trans-Furan linalool oxide & 18,52 & 18,86 & 18,72 & 18,46 & 17,80 & 18,43 & 18,51 & 16,74 & 17,18 & 18,04 & 0,69 & 3,8 \\
\hline cis-Furan linalool oxide & 8,47 & 8,37 & 8,12 & 8,02 & 8,29 & 8,99 & 7,55 & 8,52 & 8,46 & 8,20 & 0,37 & 4,5 \\
\hline Nerol oxide & 7,73 & 7,72 & 7,72 & 7,80 & 7,44 & 7,80 & 7,54 & 7,88 & 7,53 & 7,48 & 0,15 & 2,0 \\
\hline Linalool & 373,14 & 370,88 & 371,51 & 361,97 & 353,38 & 372,91 & 359,37 & 378,19 & 366,43 & 362,81 & 7,60 & 2,1 \\
\hline Hotrienol & 80,23 & 82,62 & 83,56 & 89,88 & 85,54 & 73,92 & 83,50 & 82,98 & 85,33 & 79,04 & 4,28 & 5,2 \\
\hline alpha-Terpineol & 108,15 & 104,58 & 104,01 & 102,90 & 100,00 & 105,96 & 99,52 & 109,31 & 103,90 & 101,68 & 3,20 & 3,1 \\
\hline trans-Pyran linalool oxide & 64,42 & 62,14 & 63,09 & 62,65 & 60,72 & 64,73 & 60,20 & 64.59 & 63,38 & 62,05 & 1,57 & 2,5 \\
\hline cis-Pyran linalool oxide & 21,66 & 21,64 & 21,97 & 21,63 & 20,64 & 21,58 & 21,14 & 21,48 & 21,30 & 20,52 & 0,46 & 2,2 \\
\hline Citronellol & 27,84 & 26,64 & 26,67 & 26,46 & 25,89 & 27,73 & 25,34 & 28,82 & 27,05 & 26,07 & 1,04 & 3,9 \\
\hline Geraniol & 272,85 & 265,64 & 273,10 & 277,75 & 260,88 & 280,75 & 258,54 & 278,77 & 274,48 & 268,17 & 7,57 & 2,8 \\
\hline Terpene diol-1 & 248,02 & 242,80 & 243,97 & 242,13 & 220,65 & 263,82 & 235,85 & 237,42 & 244,00 & 246,80 & 10,83 & 4,5 \\
\hline Terpene diol-2 & 16,99 & 17,08 & 18,24 & 18,60 & 17,25 & 18,93 & 17,14 & 18,07 & 17,66 & 16,04 & 0,87 & 4,9 \\
\hline trans-Geranic acid & 260,11 & 244,11 & 242,35 & 240,48 & 235,79 & 247,95 & 224,21 & 266,41 & 241,17 & 232,30 & 12,44 & 5.1 \\
\hline
\end{tabular}

"The wine was extracted independently ten times and each extract analysed

Terpene concentrations are expressed as relative concentrations, calculated with the same calibration factor, i.e. $F_{a}=1$ 
ever, also regarded as acceptable for capillary gas chromatography. In the case of wine, the standard deviations of the terpenes analysed varied between $2,0 \%$ and $5,2 \%$ (Table 3). Nerol and limonene concentration could not be analysed in wine, due to overlapping of their peaks with other peaks.

Reproducibility of gas chromatographic terpene analyses may be affected by various factors of which the final concentration step of freon extracts certainly is of great importance. Contrary to juice extracts, wine extracts cannot, under the conditions of this method, be concentrated beyond a certain point, because of the presence of high concentrations of higher alcohols. This difference in concentration ability between juice and wine extracts would certainly affect the degree of volatile evaporation and therefore reproducibility of gas chromatographic analyses. It is of great importance to retain partial reflux throughout the concentration of freon extracts in order to prevent or delay evaporation of aroma volatiles. Compounds which occur in very low concentrations may also result in inaccurate measurements during integration and consequently poor reproducibility of analyses.

Repeatability of gas chromatographic retention times

TABLE 4

Variation in gas chromatographic retention times of terpenes in Muscat d'Alexandrie wine, analysed ten times over a period of 20 days.

\begin{tabular}{l|r}
\hline \multicolumn{1}{c|}{ Terpene } & $\begin{array}{l}\text { Variation in } \\
\text { retention time } \\
\text { (min.) }\end{array}$ \\
\hline trans-Furan linalool oxide & $34,10-34,14$ \\
cis-Furan linalool oxide & $37,21-37,26$ \\
Nerol oxide & $37,54-37,58$ \\
2-Ethyl hexanol (internal standard) & $40,63-40,68$ \\
Linalool & $47,43-47,48$ \\
Hotrienol & $54,34-54,39$ \\
alpha-Terpineol & $63,00-63,06$ \\
trans-Pyran linalool oxide & $67,90-67,97$ \\
cis-Pyran linalool oxide & $71,21-71,27$ \\
Citronellol & $72,27-72,33$ \\
Geraniol & $80,94-81,04$ \\
Terpene diol-1 & $90,93-91,02$ \\
Terpene diol-2 & $108,75-108,83$ \\
trans-Geranic acid & $127,23-127,32$ \\
& \\
\hline
\end{tabular}

of terpenes in the same wine sample analysed over 20 days is given in Table 4 .

This clearly shows that the variation in retention time of the relevant terpenes was minimal $(0,04-0,1$ minutes).

The storage ability of a concentrated freon extract of terpenes in Muscat d'Alexandrie wine is demonstrated by the data in Table 5 .

The concentrated wine extract was kept at minus $12^{\circ} \mathrm{C}$ for six days and analysed daily. The relevant terpene concentrations remained practically constant for the test period and their standard deviations varied between $0,3 \%$ and $12,5 \%$ (Table 5 ). The higher standard deviations for terpene diol-1 and hotrienol could be explained by the fact that terpene diol-1 is relatively unstable and may easily rearrange in an acid medium during gas chromatographic injection to, amongst others, hotrienol and nerol oxide (Usseglio-Tomasset \& Di Stefano, 1980).

Although the above-mentioned results clearly demonstrate the possibility of keeping concentrated wine extracts, it would nevertheless be safer to store freon extracts in a diluted form and to analyse them as soon as possible after concentration. This would especially apply to grape juice extracts where volumes are normally small.

Further studies to quantify some terpenes in juice and wine in terms of actual concentrations should be undertaken.

\section{LITERATURE CITED}

MARAIS, J., 1983. Terpenes in the aroma of grapes and wines: A review. S. Afr. J. Enol. Vitic. 4, 49-60.

RAPP, A., HASTRICH, H. \& ENGEL, L., 1976. Gaschromatographische Untersuchungen über die Aromastoffe von Weinbeeren. I. Anreicherung und kapillarchromatographische Auftrennung. Vitis 15, 29-36.

SCHREIER, P. \& DRAWERT, F., 1974. Gaschromatographischmassenspektrometrische Untersuchung flüchtiger Inhaltsstoffe des Weines. V. Alkohole, Hydroxy-Ester, Lactone und andere polare Komponenten des Weinaromas. Chem. Mikrobiol. Technol. Lebensm. 3, 154-160.

USSEGLIO-TOMASSET, L. \& DI STEFANO, R., 1980. Profilo aromatico del Moscato bianco del Piemonte. Riv. Vitic. Enol. 33, 58-68.

WILLIAMS, P.J., STRAUSS, C.R. \& WILSON, B., 1980. Hydroxylated linalool derivatives as precursors of volatile monoterpenes of muscat grapes. J. Agric. Food Chem. 28, 766-771.

TABLE 5

Storage ability of a concentrated freon extract of terpenes in Muscat d'Alexandrie wine analysed daily.

\begin{tabular}{|c|c|c|c|c|c|c|c|c|}
\hline \multirow[b]{2}{*}{ Terpene } & \multicolumn{6}{|c|}{ Terpene concentration $(\mu \mathrm{g} / l)$} & \multicolumn{2}{|c|}{$\begin{array}{l}\text { Standard } \\
\text { deviation }\end{array}$} \\
\hline & Day 1 & Day 2 & Day 3 & Day 4 & Day 5 & Day 6 & $\mu \mathrm{g} / l$ & $\%$ \\
\hline trans-Furan linalool oxide & 18,04 & 18,21 & 18,03 & 17,92 & 18.29 & 18,07 & 0,13 & 0,7 \\
\hline cis-Furan linalool oxide & 8,20 & 8,26 & 8,66 & 8,79 & 8.72 & 8.86 & 0.28 & 3.3 \\
\hline Nerol oxide & 7.48 & 7,46 & 7,54 & 7.48 & 7.42 & 7,45 & 0,04 & 0.5 \\
\hline Linalool & 362,81 & 364.41 & 361,14 & 364.15 & 363,49 & 364,22 & 1,24 & 0.3 \\
\hline Hotrienol & 79,04 & 93,63 & 67,58 & 75,52 & 70.65 & 70,17 & 9.53 & 12,5 \\
\hline trans-Pyran linalool oxide & 62,05 & 62,61 & 61,64 & 62.32 & 62.37 & 62,17 & 0.33 & 0.5 \\
\hline cis-Pyran linalool oxide & 20,52 & 20,90 & 20,57 & 20,77 & 20,30 & 20,24 & 0.26 & 1.3 \\
\hline Citronellol & 26,07 & 26.84 & 25,53 & 26,13 & 26,37 & 26,47 & 0,44 & 1,7 \\
\hline Geraniol & 268.17 & 270.88 & 263,35 & 265,99 & 267,68 & 268.04 & 2,51 & 0,9 \\
\hline Terpene diol-1 & 246,80 & 219,67 & 267,44 & 258,03 & 267,91 & 267,18 & 18.94 & 7,4 \\
\hline Terpene diol-2 & 16,04 & 15,32 & 17.53 & 17,18 & 17,18 & 17,36 & 0.88 & 5,3 \\
\hline trans-Geranic acid & 232,30 & 234.69 & 227,12 & 233,91 & 231,81 & 233,40 & 2.70 & 1.2 \\
\hline
\end{tabular}

Terpene concentrations are expressed as relative concentrations, calculated with the same calibration factor, i.e. $F_{a}=1$. 